\title{
Global Aging, Well-Ordered Science, and Prospection
}

\author{
Colin Farrelly
}

\begin{abstract}
Aristotle described the study of politics as an "architectonic" science that aspires to bring together insights from different fields of scientific inquiry to ensure that citizens have the opportunities to flourish. To meet the health and economic challenges of aging populations, we must revive this Aristotelian vision of politics. Prioritizing biogerontology is a requirement of well-ordered science. But a number of cognitive limitations and biases impair our ability to perceive both the harms of the inborn aging process and the magnitude of the likely benefits of age retardation. Thus, well-ordered science also requires us to address the social and cultural, and not merely scientific, obstacles that impede the aspiration to retard human aging.
\end{abstract}

\section{Introduction}

$\mathbf{P}$ OlitiCAL SCIENCE IS A METHODOLOGICALly diverse social science that aspires to bring together knowledge from distinct fields of scientific inquiry (e.g., economics, psychology, etc.) with the ultimate goal of elucidating what constitutes good governance. The Greek philosopher Aristotle, who was the first political scientist, described politics as a normative, prescriptive science that is ultimately concerned with the good of humans. As such, Aristotle considered politics as an architectonic science, for it is politics "which ordains which of the sciences should be studied in the state, and which each class of citizen should learn and up to what point they should learn them" (NE 1.1.1094). ${ }^{1}$

Aristotle believed that a student of politics should be most concerned with what preserves and destroys a polis, or citystate. And more than 2,000 years after Aristotle outlined this vision of politics as an architectonic science, the health and economic challenges facing human populations have changed dramatically. A determination of which sciences ought to be studied, and how science could improve the health prospects of the world's aging populations, is imperative, but it is also challenging. It is imperative because an unprecedented number of humans are expected to suffer the chronic diseases of aging this century. And it is challenging because we possess a number of cognitive limitations and biases that impair our ability to perceive both the harms of the inborn aging process, as well as the magnitude of the likely benefits of age retardation.

\section{Well-Ordered Science}

Nearly a century ago, the American pragmatist John Dewey remarked that "science is still too recent to have been absorbed into imaginative and emotional disposition." ${ }^{2}$ Because our imaginative and emotional dispositions are the product of our evolutionary history, it can be very difficult to modify them. Thus, Dewey's comment is still apt today. Government policies that explicitly evoke stakes that have ancient emotive roots in our psychology, like concerns over security (e.g., crime and terrorism) or reciprocity (e.g., welfare reform), are likely to form the basis of the principles and policies of political parties pandering to the preferences of the majority in the hopes of winning an election. But because the stakes involved with sound science policy are sometimes less vivid, and often long term, this can impede the realization of well-ordered science.

"The pursuit of science in a society is well-ordered when the research effort is efficiently directed toward the questions that are most significant." ${ }^{3}$ One of the most significant questions for the medical sciences today is "why are old cells more vulnerable to disease than are young cells?" ${ }^{4}$ And the most efficient strategy for tackling the chronic diseases of aging would be to modulate the aging process itself, rather than the current approach of trying to eliminate every specific disease of aging. To realize the importance biogerontology has for global health, one must have a solid grasp of the current and future state of global health. And a variety of cognitive limitations and biases can skew our ability to form accurate representations of both the present and the future. These limitations and biases are themselves obstacles to well-ordered science.

Aspiring to tackle the inborn aging process itself, rather than just the specific diseases of aging, is both a pressing and a serious challenge. Tackling aging is a serious challenge not merely because aging is a complex process that has only recently entered the mainstream of biological inquiry, but

Department of Political Studies, Queen's University, Kingston, Ontario, Canada. 
also because aging is a novel health threat in two important respects. First, it is only over the past century or so that aging has become a serious health threat to the world's populations. Unlike poverty, infectious disease, and violence, which have plagued human civilizations for millennia, the high prevalence of the chronic diseases of aging is a very recent phenomenon in our species' history. Second, the inborn aging process is a novel health threat because it cannot (at least easily) be detected by the innate "risk sensors" we have inherited from our Darwinian past (i.e., our five senses), nor is aging itself something that the traditional tools of epidemiology are well designed to identify as a health threat.

Epidemiology focuses primarily on the proximate causes of disease, something that is very effective in combating infectious disease but less useful in helping to tackle chronic diseases like cancer, heart disease, or Alzheimer disease. Aging is the product of evolutionary neglect, and as such it is difficult for us to perceive it as the problem that it really is. And thus a vital component of well-ordered science is the development of new "risk detectors," so that we can overcome the cognitive limitations and biases that impede us from responding to aging in a way that is proportionate to the threat it now poses to human health.

If we are to ensure that the societies of today's aging populations are to thrive and flourish this century, we must revive the Aristotelian vision of politics that seeks to bring together insights from many distinct fields of inquiry, including demography, biogerontology, and psychology. A new model of health promotion and disease prevention is needed for the 21st century, ${ }^{5}$ a model that prioritizes the study of aging. To realize that model we must overcome a number of obstacles which arise because of misperceptions about the present and future.

\section{(Mis)Perceptions About the Present}

When Aristotle was alive in the $4^{\text {th }}$ century BC, life expectancy for humans was, like it was for the vast majority of our species' history, below the age of 30 . High rates of early and midlife morbidity and mortality, caused by infectious diseases, poverty, war, etc., meant that very few humans experienced aging. "Prehistoric human remains have never revealed individuals older than about 50 years of age, and humans had a life expectancy at birth of 30 years or less for more than $99.9 \%$ of the time that we have inhabited this planet." ${ }^{4}$ It is only over the last century that humanity has escaped-thanks mainly to advances in technology (e.g., the sanitation revolution), medical knowledge, material resources, and changes in behavior-a world dominated by early and midlife morbidity and mortality.

Over the past 200 years, life expectancy for humans born into the world has more than doubled. By the end of the twentieth century, "with more than six billion people alive, life expectancy reached nearly sixty-seven years amidst a continuing rise." ${ }^{\prime 6}$ And there are currently 737 million persons age 60 or older world-wide; it is estimated that by 2050 that number will rise to 2 billion persons, the vast majority of them in the developing world. ${ }^{7}$

The greatest single threat to the health prospects of today's aging populations is the inborn aging process itself. However, many cognitive limitations and biases impair our ability to accurately perceive this reality. One cognitive bias is the availability heuristic. ${ }^{8}$ The more vivid particular harms and risks are in our mind, the more likely we are to overestimate the probability of their occurring. Because most people in the developed world form their perceptions of life in developing countries from what they see and hear in the media (e.g., reports on the evening news), they often assume that most people who die in lower- and middle-income countries die from infectious diseases (like HIV or malaria), poverty or violence (e.g., war or homicide). But the deaths reported in the media are not representative deaths. Representative deaths, like death due to cancer, heart disease, and stroke, are not usually deemed "news worthy" by the media (unless they are the deaths of celebrities).

The data provided in Fig. 1, from the World Health Organization (WHO) estimates on the causes of death in the world in 2005, provide an accurate account of the causes of death in the world. And the majority of those deaths are due to chronic disease.

Contrary to what many people in the developed world might believe, the diseases that kill most people in their own country, like heart disease, cancer, and stroke, are also prevalent in lower- and middle-income countries. In fact, most deaths from chronic disease occur in lower middleincome countries. The WHO estimates that between the years 2005 and 2015, 76 million people will die from chronic illness in high income countries. ${ }^{9}$ But the number is even higher for the more populous lower middle-income countries, like China and India. It is estimated that in that same 10-year period chronic illness will cause 144 million deaths in these lower middle-income countries. ${ }^{10}$ WHO estimates that $75 \%$ of all the chronic disease deaths in the world occur among people that are over the age of 60 . Thus, age is the biggest risk factor for developing disease in the world today, which is why well-ordered science necessitates that we prioritize biogerontology and the goal of age retardation.

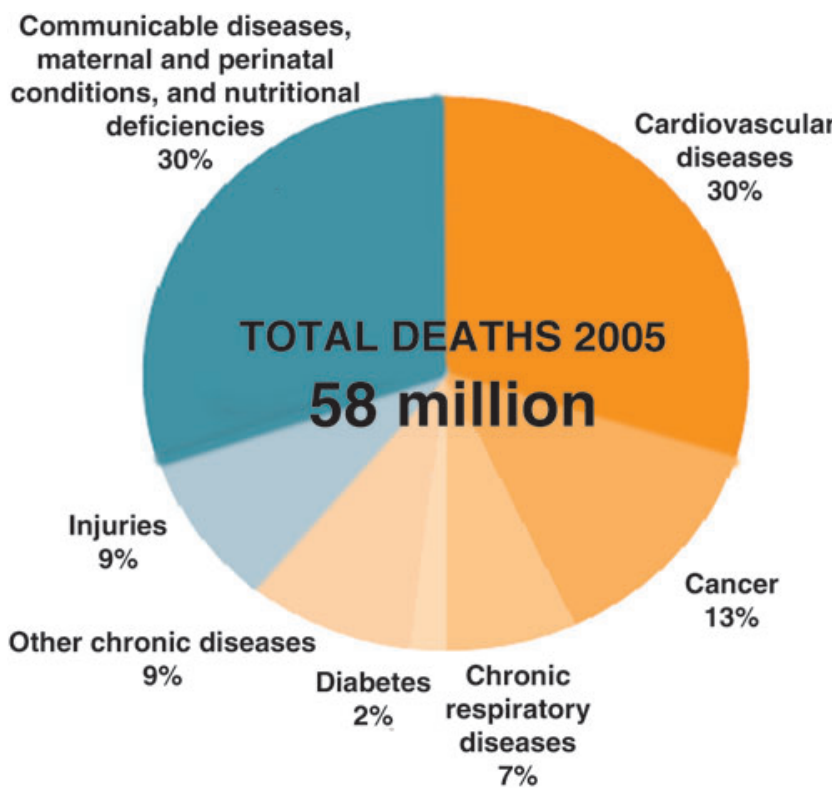

FIG. 1. Projected main causes of death worldwide in 2005 for all ages. Source: World Health Organization, Preventing Chronic Diseases: A Vital Investment. ${ }^{11}$ 
Table 1. Distribution of World Population by Life Expectancy, 1960-199912

\begin{tabular}{lccccr}
\hline & $\begin{array}{c}\text { Life expectancy } \\
\text { at birth in 1960 }\end{array}$ & $\begin{array}{c}\text { Life expectancy } \\
\text { at birth in 1999 }\end{array}$ & $\begin{array}{c}\text { Percentage } \\
\text { change }\end{array}$ & $\begin{array}{c}\text { Relative to 1960 } \\
\text { average percent }\end{array}$ & $\begin{array}{r}\text { Relative to 1999 } \\
\text { average percent }\end{array}$ \\
\hline Quintile 1 & 35.9 & 53.0 & +48 & 72 & 80 \\
Quintile 2 & 39.9 & 63.7 & +60 & 80 & 96 \\
Quintile 3 & 44.5 & 68.6 & +54 & 118 & 103 \\
Quintile 4 & 59.0 & 70.3 & +19 & 141 & 106 \\
Quintile 5 & 70.1 & 76.8 & +10 & 116 \\
\hline
\end{tabular}

One of the misunderstandings about chronic disease highlighted in the WHO's report Preventing Chronic Diseases: A Vital Investment is misunderstanding \#9: That low- and middle-income countries should control infectious diseases before chronic diseases. But this strategy is irrational given the reality of the health challenges facing these aging populations. The report notes:

In reality, low and middle income countries are at the centre of both old and new public health challenges. While they continue to deal with the problems of infectious diseases, they are in many cases experiencing a rapid upsurge in chronic disease risk factors and deaths, especially in urban settings. These risk levels foretell a devastating future burden of chronic diseases in these countries. ${ }^{11}$

It is perhaps natural for us to think that infectious diseases that kill the young should be eliminated before we address diseases that typically afflict people in later life. But it would be irrational (and immoral) for countries to adopt such a narrow approach to health promotion. Aspiring to only reduce a person's risk of disease and death in early life, but then condemning them to disease and frailty in late life, presumes that health has diminishing marginal utility for persons the older they get. But health is not like wealth. Additional years of healthy life do not cease to add value to a person's wellbeing simply because that person has enjoyed more years of health than others might have enjoyed. We all hope to wake up healthy tomorrow, no matter what age we are.

Furthermore, the current strategy of the medical sciences, which is to tackle each specific disease of aging (rather than aging itself), is inefficient given the plurality of problems that afflict us in late life. "Now that comorbidity has become the rule rather than the exception, even if a "cure" was found for any of the major fatal diseases, it would have only a marginal effect on life expectancy and the overall length of healthy life." ${ }^{5}$ Well-ordered science requires a polity to invest in the science that would be the most effective in promoting the health prospects of a population. Misperceptions about what causes most chronic disease in the world today thus impair the realization of well-ordered science. Rather than focusing almost exclusively on the proximate causes of chronic disease (like tobacco, diet, etc.), we must also address the evolutionary causes of late-life morbidity and mortality. This would lead us to see the importance of the biology of aging. An intervention that slowed the rate of molecular and cellular decline, thereby simultaneously delaying the afflictions of aging, would be one of the most important innovations in medicine.

In addition to presuming that infectious diseases, rather than chronic diseases of aging, are the leading causes of death in the developing world, many often assume that global health inequalities are expanding. But the reality is they are declining, due in large part to the inborn aging process. This becomes evident when one considers the trend of global health inequalities through a diachronic, rather than synchronic, lens. In the second half of the twentieth century the gap in life expectancy between the richest quintile of the global population and the poorest quintile actually declined, as illustrated in Table $1 .^{12}$

Life expectancy at birth in the richest quintile was 70 years in 1960, and this rose by $10 \%$ over the next 40 years. Contrast that with the gain in life expectancy for the poorest quintile. The poorest quintile experienced a $48 \%$ increase in life expectancy during this same time frame, increasing the life expectancy from 36 years in 1960 to 53 years by 1999. Furthermore, these gains were made in spite of the severe challenges infectious diseases, especially human immunodeficiency virus/acquired immunodeficiency syndrome (HIV / AIDS), posed. While AIDS is still a major global health priority, the latest epidemiological data suggests that things are improving. "The spread of HIV appears to have peaked in 1996, when 3.5 million (3.2 million to 3.8 million) new HIV infections occurred. In 2008, the estimated number of new HIV infections was approximately 30\% lower than at the epidemic's peak 12 years earlier." ${ }^{13}$ The United Nations report on the AIDS epidemic estimates that antiretroviral therapy has added approximately 11.7 million life-years globally between 1996 and 2008. And this number is expected to continue to rise as antiretroviral programs continue to expand.

If we turn our attention to the other end of the life expectancy spectrum, we must ask why has the dramatic increase in wealth in the four decades from 1960 to 1999 not brought the richest countries a much more sizable gain in life expectancy? The reason for this is that these countries have now come up against the limits of the inborn aging process. It is much easier to translate wealth into reductions in early and mid-life morbidity and mortality. But it is proving to be much harder to make significant gains against the chronic diseases of aging by following lifestyle changes or reducing external risk factors (e.g., tobacco). While exercise can help delay disease and increase life expectancy, these benefits are very modest compared to the benefits conferred by the public health measures which reduced the risks of early and midlife morbidity. "Moderate and high physical activity levels have been demonstrated to lead to 1.3 and 3.7 years more in total life expectancy and 1.1 and 3.2 more years lived without cardiovascular disease." 14

The misperception that health inequalities are expanding rather than constricting is itself a significant obstacle to the 
realization of well-ordered science. Many will object to prioritizing biogerontology because they will consider it distasteful, if not unjust, to concern ourselves with tackling aging when so many more people are vulnerable to death in early life. Such a sentiment was recently expressed by a general practitioner commenting on the "Rapid Response" website $^{15}$ for the British Medical Journal. Commenting on a paper that called for a greater investment in aging research, the general practitioner argued that it "seems faintly distasteful that we should be striving to extend life at the upper limit when so many millions have it snuffed out long before any 'natural' lifespan, and not because of the ageing process but because of infectious disease, malnutrition, inadequate hygiene, absence of basic midwifery care etc." This same commentator also claimed that "the logical outcome of the 'advances' [ in slowing aging]... would surely be extension of active life and corresponding high consumption by wealthy populations with their high carbon footprint-at the expense of the poor."

These comments take us nicely to the topic of our ability (or rather our inability) to make accurate and sensible predictions about the future-what psychologist Daniel Gilbert calls "prospection."16 Prospection refers to our ability to "pre-experience" the future by simulating it in our minds. ${ }^{17}$ The fact that we are prone to a number of errors of prospection is also a significant obstacle to our realizing wellordered science.

\section{(Mis)Perceptions About the Future}

Our perception of the future, like that of the present, can be skewed by a variety of cognitive limitations and biases. This creates unique challenges for the field of biogerontology. When thinking about the future, people use their immediate hedonic reactions to simulations as predictors of the hedonic reactions they are likely to have when the events they are simulating actually come about. ${ }^{17}$ So if asked to simulate what a future with no cancer would be like, a person is likely to have a positive emotive response. The same would no doubt be true for eliminating any specific disease of aging, like Alzheimer disease, stroke, or diabetes. However, if asked to simulate what a future of slowed human aging would entail, our deliberations are likely to fall prey to some common prospection errors because of the complexities and indeterminacies of such a simulation exercise. Thus, biogerontologists often face what Richard Miller calls "gerontologiphobia" - "the irrational fear that ageing research is a public menace bound to produce a world filled with nonproductive, chronically disabled, unhappy senior citizens consuming more resources than they produce." $^{\prime 18}$

One common prospection error is that simulations are unrepresentative. ${ }^{17}$ Simulations of the future are constructed from our memories. So when we construct a simulation of a cancer-free world we invoke our memories of the tragic costs of cancer. Thus, the simulation of a cancer-free future will invoke an automatic hedonic response. But when asked to consider what a future of decelerating human aging would entail, people are likely to invoke the negative memories of aging (e.g., being frail) and assume that slowing aging would simply prolong the period of frailty in late life, hence the prevalence of gerontologiphobia.
Concerns that extending the human life span would exacerbate global health inequalities also suffer from this unrepresentative simulation error. If the memory most people in the developing world have of global health inequalities is that they have increased over the past half century (rather than decreased), then it will be natural for them to think that such inequalities will be further exacerbated in the future. And this "greater inequality" simulation will be reinforced by the misperception that most deaths in the developed world are caused by poverty, war, and infectious disease (rather than aging), hence the kind of negative reaction noted above from the general practitioner.

To combat the unrepresentative prospection error it is imperative that the realities of today's health challenges, the trend of health inequalities, and the effects of decelerating aging, be emphasized. Simulations of the future are premised on memories. But if very few people in the developed world have a memory of the reality that aging causes disease and death in developing countries today, then they will find it hard to simulate the health benefits age retardation would have on the 1.5 billion persons who will be over the age of 60 and living in developed counties by the middle of this century.

Another common prospection error is that simulations are abbreviated. ${ }^{17}$ This means that our simulations of the future typically focus on a few, select moments of a future event. When asked to simulate a future with no cancer, for example, our abbreviated simulations are likely to focus on the fact that many lives would be saved. It is a clear and simple simulation to make, and the hedonic response is immediate. But if asked to simulate a future where human life expectancy is increased by retarding human aging, simulations are likely to focus on the potential adverse consequences of populations living longer, like overpopulation or climate change. Because simulations of the future typically focus on a few variables, we are likely to overlook the fact that there would be time and opportunity to undertake adaptations that could reduce the potential adverse consequences of extending the human life span, like reductions in fertility rates and the development of renewable energies. The prevalence of gerontologiphobia is thus perhaps partly due to the fact that abbreviated simulations of an aging intervention lead people to focus exclusively on the impact of an increase in the number of (old) people, rather than the benefits a reduction in chronic disease would bring.

A more accurate and balanced simulation of age retardation would consider the benefits of people enjoying more mobility and independence, more time with loved ones, and more opportunities to make important contributions to their communities. Such details can be ignored by the abbreviation error. And this is why proposals like detailing the "Longevity Dividend"19 are a vital part of well-ordered science.

\section{Health is Not a Zero-Sum Game}

Finally, a factual error that can arise in the context of prospection about prioritizing biogerontology is that critics falsely assume health is a zero-sum game. "In zero-sum games, the fortunes of the players are inversely related. In tennis, in chess, in boxing, one contestant's gain is the other's loss. ${ }^{\prime 20}$ The tendency to view social cooperation in terms of 
a zero-sum game is perhaps an ancient evolved emotive response that first arose when our species lived in conditions where health and wealth was a zero-sum game. Bruce Charleton, for example, has argued that the "the inequity of inequality" has its basis in human nature. ${ }^{21}$ In "immediate return" economies, where the bounty of a group hunt would be consumed by members of a tribe, someone's gain would be another's loss. So if you take the lion's share of the day's bounty then there would be less for others to eat.

The egalitarian and counterdominance instincts that evolved to help make cooperation possible in immediate return economies still informs our moral psychology, despite the fact that our societies are now much more complex. "This continued ethos of equal shares presumably underlies the endemic sense of the injustice of hierarchies which fuels an intractable social dissatisfaction concerning differentialsincluding the identification of health inequalities as a potentially problematic state of affairs." ${ }^{21}$

Once the ancestral foundations of this moral intuition have been identified and elucidated, advocates of biogerontology will be better positioned to help alleviate these concerns. Rather than propose tackling aging as a way of "increasing life span," it would be more prudent to redescribe the aspiration as one that seeks to prevent or treat disease. Proposing to add yet more years to the life span of those who have escaped early and midlife morbidity will more likely trigger counterdominance instincts than describing the goal as one of disease prevention. It is much harder to perceive those most at risk of chronic disease as "dominators" who threaten to upset an egalitarian ethos of health.

"This perception of the inequity of inequality is extremely powerful, even in those affluent societies where access to resources is continually rising across all social groups."21 Thus, some bioethicists reach the conclusion that further increases to human life expectancy would not be necessary or desirable. Daniel Callahan, for example, argues:

The average person in good health in the developed countries of the world (and living in a reasonably safe environment), already lives long enough to accomplish most reasonable ends.... Neither the human species as a whole, nor most individuals, need more than the present average life expectancy in the developed countries (the mid-seventies to low-eighties) for a perfectly satisfactory life. This idea of a steady-state life expectancy at its present level would establish, happily, a finite and attainable goal: "Enough, already." 22

Talk of improvements (i.e., increasing life span) can trigger counterdominance instincts, but this is less likely to be the case if one invokes the language of protection (e.g., reducing the risk of disease). Consider, for example, the case of exercise. As noted earlier, exercising has been shown to add between 1.3-3.7 years to total life expectancy by reducing the risks of cardiovascular disease. No one would complain that it is unfair or unethical that the elderly should enjoy the further health advantage exercise confers just because there are young people who die from cancer or diabetes. It would be unimaginable to invoke attitudes like "enough, already" in such a context. Why is that the case? Part of the reason might be that exercise is perceived as an intervention that helps prevent harm rather than something that confers a benefit. Furthermore, it is a benefit that is not perceived to come from the "collective pool" of potential health benefits. So my gaining extra health by exercising regularly does not result in taking away some of the health available to others. But if the benefit comes about via a pill or medical procedure done in a hospital, people are more likely to invoke the "health is a zero-sum game" framework.

What this suggests is that it is important to "frame" the stakes involved with senescence and biogerontology appropriately. ${ }^{23}$ Rather than asking, as Callahan does, if the current life expectancy is high enough or not, the real questions to consider should be framed as follows: Are the current rates of chronic disease too high, or too low? What is the acceptable incidence rate for cancer, heart disease, and stroke? Is it acceptable, for example, that the death rate among Americans ages $80-84$ is 6,712.9 per 100000 persons, which is 10 times higher than the death rate for babies in the first year of life, 463 times higher than the proportion of deaths among children ages 5-9, and almost 69 times higher than the death rate among adults in their 20 s $^{24}$ Is it acceptable that $31.7 \%$ of Americans over the age of 65 have reported they have heart disease, $51.9 \%$ report having hypertension, $20.6 \%$ cancer, $17 \%$ diabetes, and $49.9 \%$ arthritis? ${ }^{25}$ Is it acceptable that $47.7 \%$ of men over 65 and $33.9 \%$ of women report they had trouble hearing? Once the harms of senescence are made explicit in this way it is much harder to invoke counterdominance instincts to assail biogerontology without sounding obviously ageist and/or malice. Is "enough, already" really an appropriate response to the aspiration to help reduce late-life morbidity and mortality? No it is not. Just as it would not be an appropriate response to the moral imperative to help reduce early or midlife morbidity and mortality.

\section{Conclusion}

To ensure the societies of today flourish, we must revive the Aristotelian vision of politics as a normative, practical science. Senescence poses enormous challenges to the health and economic prospects of today's aging populations. Meeting these challenges requires us to advance our knowledge, not only about the biology of aging and how to minimize the harms of senescence, but also about the cultural and social obstacles that impede our ability to tackle aging. These include misperceptions about the threat the inborn aging process poses to those living in both rich and poor countries, misperceptions about the trends of global health inequalities, and misperceptions about what the goal of biogerontology is (e.g., extending the health span versus extending the number of years of frailty).

There are also misperceptions about what the potential consequences of age retardation might be. Prospection can be skewed by simulations that are unrepresentative and abbreviated. To help individuals overcome these prospection errors, it is important to emphasize the diverse benefits age retardation would confer on individuals in both rich and poor countries. Slowing aging would provide individuals with greater opportunities for health and independence. And this would yield significant economic benefits. As the WHO's 1997 Brasilia Declaration on Ageing emphasized, "healthy older persons are a resource for their families, their communities and the economy." 26 
Our susceptibility to cognitive biases and errors, like our susceptibility to the diseases of aging, has been shaped by our Darwinian past. To meet the challenges facing today's aging populations, we must tackle both the scientific and sociocultural obstacles that impede well-ordered science. Reviving the Aristotelian vision of politics as a science concerned with the good of humans, and one that strives to bring together knowledge from distinct fields of scientific inquiry, can help us ensure that we are better positioned to meet the challenges facing the world's aging populations.

\section{Acknowledgment}

I would like to thank two referees from this journal for their constructive feedback on an earlier version of this paper.

\section{References}

1. Aristotle. Nicomachean ethics. In Ackrill JL (ed): A New Aristotle Reader. Princeton University Press, Princeton, NJ, 1987.

2. Dewey J. Democracy and Education. Macmillan, New York, 1916, p 262.

3. Flory JH, Kitcher P. Global health and the scientific research agenda. Philos Public Aff 2004;32:36-65.

4. Hayflick L. The future of ageing. Nature 2000;408:267-269.

5. Butler RN, Miller RA, Perry D, Carnes BA, Williams TF, Cassel C, Brody J, Bernard MA, Partridge L, Kirkwood T, Martin GM, Olshansky SJ. New model of health promotion and disease prevention for the 21st century. Br Med J 2008;337:149-150.

6. Riley J. Rising Life Expectancy: A Global History. Cambridge University Press, New York, 2001.

7. United Nations. Population ageing and development 2009. Accessed at http://www.un.org/esa/population/ publications/ageing/ageing2009chart.pdf/.

8. Tversky A, Kahneman D. Availability: A heuristic for judging frequency and probability. Cogn Psychol 1973;5: 207-232.

9. See http://www.who.int/chp/chronic_disease_report/ media/hi_income.pdf/.

10. See http://www.who.int/chp/chronic_disease_report/ media/lower_middle.pdf/.

11. World Health Organization. Preventing Chronic Disease: A Vital Investment. WHO, Geneva, 2005.
12. Palacious R. The future of global ageing. Int J Epidemiol 2002;31:786-791.

13. UNAIDS. AIDS Epidemic Update: November 2009. WHO, Geneva, 2009.

14. Franco O, de Laet C, Peeters A, Jonker J, Mackenbach J, Nusselder W. Effects of physical activity on life expectancy with cardiovascular disease. Arch Intern Med. 2005;165: 2355-2360.

15. See http://www.bmj.com/cgi/eletters/337/jul08_3/a414 \#199184/.

16. Gilbert DT. Stumbling on Happiness. Knopf, New York, 2006.

17. Gilbert DT, Wilson TD. Prospection: Experiencing the future. Science 2005;317:1351-1354.

18. Miller R. Extending life: Scientific prospects and political obstacles. Milbank Q 2002;80:155-174, 170.

19. Olshansky SJ, Perry D, Miller RA, Butler RN. The longevity dividend. The Scientist 2006;20:28-36.

20. Wright R. Nonzero: The Logic of Human Destiny. Vintage Books, New York, 2000.

21. Charlton B. The inequity of inequality. J Health Psychol 1997;2:413-425.

22. Callahan D. False Hopes: Why America's Quest for Perfect Health Is a Recipe for Failure. New York: Simon and Schuster, 1998.

23. Farrelly C. Framing the inborn aging process and longevity science. Biogerontology 2010;11:377-385.

24. http://www.cdc.gov/nchs/data/nvsr/nvsr56/nvsr56_10.pdf/.

25. Federal Interagency Forum on Aging-Related Statistics, Older Americans update 2006:key indicators of well-being. Washington, DC: Federal Interagency Forum on AgingRelated Statistics, 2006, 24. This report is available online at http://www.agingstats.gov/agingstatsdotnet/Main_Site/ Data/2006_Documents/OA_2006.pdf/.

26. World Health Organization. The Brasilia declaration on ageing. Health Promo Int 1997;12:175-178.

Address correspondence to: Dr. Colin Farrelly

Department of Political Studies Queen's University 99 University Ave Kingston, Ontario, Canada K7L 3N6

E-mail: farrelly@queensu.ca 